\title{
THE APPLICATION OF AN \\ ENGINEERING BASED METHODOLOGY \\ TO ORGANISATIONAL DIVERSIFICATION \\ AND REFOCUSING \\ - AN OVERVIEW
}

\author{
Pierre Leonard ${ }^{1}$ and
}

Paul Kruger

\author{
Department of Industrial and Systems Engineering \\ University of Pretoria
}

\begin{abstract}
An organisation is usually bound to the various life cycles of the industries that it serves. In order to ensure sustainability over the long-term, an organisation needs to align and continuously realign itself with its changing environment. According to Thompson [6] the external environment is defined as the macro system of which an organisation is a part. It is either an integral part of the macro system, or it plays a supportive role in the macro system. Although various leading authors, top business professionals and consulting groups have different opinions regarding the use of diversification and refocusing, these seem to be alternative ways of aligning with the changing environment of the industry if used correctly. This paper will present an overview of an integrated diversification and refocusing methodology that may be used to guide organisational transformation.
\end{abstract}

\footnotetext{
'P. Leonard is currently employed by Iscor Limited as a Senior Business Consultant.
} 


\section{Introduction}

\section{"The goal of an organisation is to make money now and in the future." Eliyahu M Goldratt [1]}

It is becoming increasingly important for senior managers and corporate strategists to understand and act on the factors that influence, not only short-term profitability, but also long-term sustainability of their organisations. In the search to understand these factors and their influences, it is evident that organisations are often inevitably bound to the industries that they serve.

One of the best known and most established marketing concepts is the product life cycle [Grant: 2]. Products are born, their sales grow, they reach maturity, they go into decline and they ultimately die. If products have life cycles, so too do the industries and organisations that produce them. The industry life cycle is the supply side equivalent of a product life cycle. It can thus be reasoned that the industry life cycle, of an industry that produces a range or sequence of products, will most likely be of longer duration than that of a single product.

An organisation's external environmental change is directly related to the change in the industry or industries that it serves. In time, all the industries will change and will eventually become obsolete. According to Moll [5] the rate of environmental change (or industry change) is increasing and organisations that recognise the need to align and continuously realign seems to live longer. If the environment becomes increasingly turbulent, the ability of the organisation to adapt to the changing environmental circumstances becomes increasingly crucial. External change is an important factor that influences the destiny of an organisation.

One of the ways of addressing industry change [Leonard: 4] in order to align and continuously realign, is by diversifying into related or unrelated products / industries. Another is to refocus on specific products / industries. Over time an organisation might even evolve (through diversification or refocusing) into something completely new and different.

Moll [5] argues that many of the current approaches of addressing organisational change and transformation are often termed engineering, reengineering, innovation or redesign [Champy : 7, Davenport : 8 and 9, Hammer : 10 and 11] of the business although often having nothing to do with the engineering disciplines. The role of one or two business resources are often elevated in most of these approaches without consideration of the other factors involved and thus addresses only pieces of the puzzle. He [Moll: 5] maintains that: "There is in fact very little engineering as defined in the engineering profession, present in current approaches". Industrial Engineering is a discipline that is equipped with all the necessary skills to be a key stakeholder in business transformation issues. Industrial Engineering originated from various transformational issues that resulted from the industrial revolution. In his [Moll: 5] effort to define the underlying principles of the approach required to transform an organisation, a subject area known as Business Engineering emerged. It now serves as a theoretical home for the field that studies business transformation. 


\section{Discussion}

"... to acquire or not to acquire: that is the question."

\section{Robert J Terry}

Various leading authors, top business professionals and consulting groups have different opinions regarding the use of diversification or refocusing. This leads to misconceptions and incorrect usage of these strategic tools. Leonard [4] presented an integrated diversification and refocusing approach that has been intended to serve as a guideline to senior management and corporate strategists. This approach incorporates related business principles and the emerging engineering subject area, known as Business Engineering [Moll: 5]. Business Engineering is an engineering approach, based on applying engineering skills in addressing business transformational issues.

This integrated approach can best be illustrated as in figure 1. The process consists off three main phases, Business Analysis, Business Design and Business Transformation, that directly correlates with the Business Engineering approach, as defined by Moll [5]. Sub-processes, within the approach, specifically address the business transformational issues of diversification and refocusing.
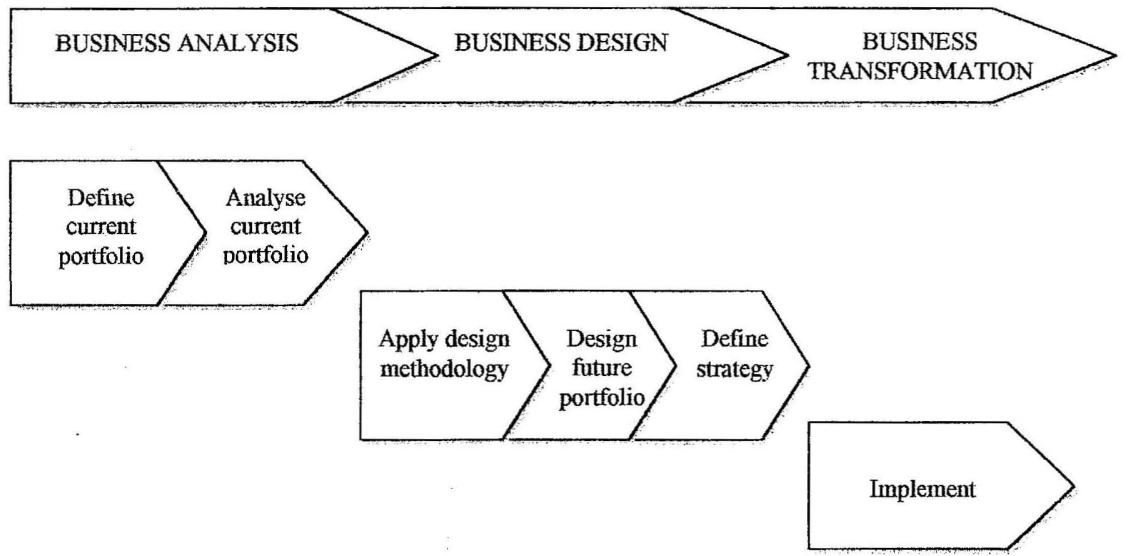

Figure 1: Diversification and Refocusing Methodology

\subsection{Business Analysis}

The Business Analysis phase starts by defining the scope of the organisation's current portfolio. Grant [2] defines an organisation's portfolio scope by :

- The range of products or commodities that the organisation's Strategic Business Units produce.

- The geographical distribution of the organisation's Strategic Business Units (local, regional, national or global).

- The extent to which the Strategic Business Units are forward or backward integrated. 
To visually illustrate the scope of an organisation's portfolio, three axes are proposed as illustrated in figure 2. As an example, an imaginary organisation's scope will be defined according to the three scope axes.

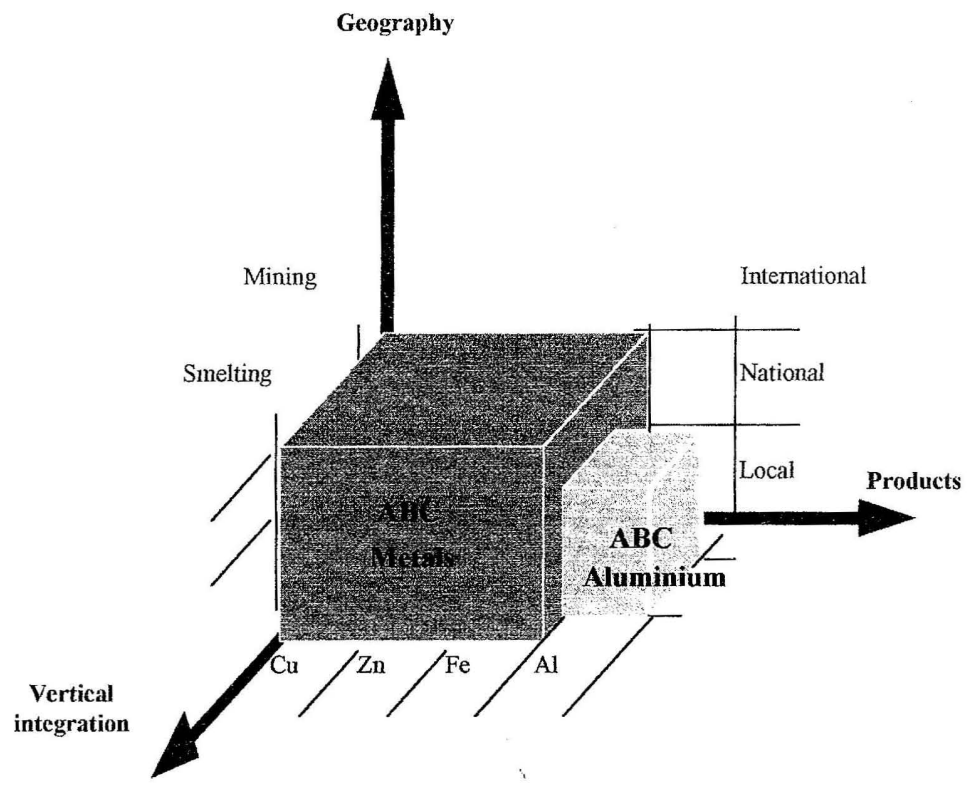

Figure 2: ABC (Pty) portfolio scope

The imaginary organisation, $A B C(P t y)$, has two Strategic Business Units, $A B C$ Metals, that is a national, integrated mining and smelting company, and $\boldsymbol{A B C}$ Aluminium, that is a local aluminium smelting company. $\boldsymbol{A B C}$ Metals is vertically integrated from mining to smelting in three products / commodities, namely Copper $(\mathrm{Cu})$, Zinc $(\mathrm{Zn})$ and Iron Ore (Fe). $A B C$ Metals' products are geographically distributed locally and nationally, but not internationally. $A B C$ Aluminium is not vertically integrated and is only in the smelting industry. It also has only one product / commodity and that is Aluminium (Al). ABC Aluminium is located locally and produces only for the local market. The two Strategic Business Units are related, based on their geographical location (locally), their smelting capabilities and also due to the fact that they are commodity based.

Once the portfolio scope has been defined, a thorough analysis of the environment should be made, in order to understand the current reality of the organisation's portfolio. A sub-process of the Business Engineering approach [Moll: 5] was adopted and is illustrated in figure 3 . 


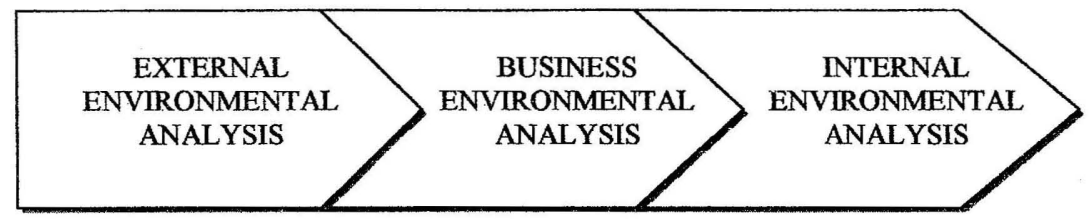

Figure 3: Business Analysis Process

One of the most critical factors to be analysed, is the institutional context of an organisation. According to a study conducted by Khanna and Paleo [3], it is the difference in institutional context that explains the successes of large, diversified corporations in developing economies such as Indonesia and India and their failure in advanced economies such as the United States and the United Kingdom. In their [Khanna and Paleo: 3] research they found that highly diversified business groups can be particularly well suited to the institutional context of most developing countries. These conglomerates can add value by imitating the functions of several institutions that are present only in advanced economies. Successful groups effectively mediate between their member companies and the rest of the economy. Table 1 illustrates how institutional context drives strategy.

By analysing the portfolio environment, as described by Moll [5] and elaborated on by Leonard [4], an understanding of the current reality of an organisation's portfolio can be made. This may also lead to the identification of strategic issues that need to be addressed in the design phase of the methodology, and may be termed design criteria from the engineering perspective. 


\begin{tabular}{|c|c|c|c|}
\hline $\begin{array}{l}\text { Institutional } \\
\text { Dimensions }\end{array}$ & United States & Japan & India \\
\hline $\begin{array}{l}\text { Capital } \\
\text { Markets }\end{array}$ & $\begin{array}{l}\text { Equity-focused, } \\
\text { monitoring by } \\
\text { disclosure rules and the } \\
\text { market for corporate } \\
\text { control }\end{array}$ & $\begin{array}{l}\text { Bank-focused, } \\
\text { monitoring by } \\
\text { interlocking } \\
\text { investments and } \\
\text { directors }\end{array}$ & $\begin{array}{l}\text { Underdeveloped, } \\
\text { illiquid equity markets } \\
\text { and nationalised banks; } \\
\text { weak monitoring by } \\
\text { bureaucrats }\end{array}$ \\
\hline $\begin{array}{l}\text { Labour } \\
\text { Markets }\end{array}$ & $\begin{array}{l}\text { Many business schools } \\
\text { and consulting firms } \\
\text { offering talent, certified } \\
\text { skills enhance mobility }\end{array}$ & $\begin{array}{l}\text { Few business schools, } \\
\text { training internal to } \\
\text { companies, company- } \\
\text { specific development } \\
\text { of talents }\end{array}$ & $\begin{array}{l}\text { Few business schools } \\
\text { and little training, } \\
\text { management talent } \\
\text { scarce }\end{array}$ \\
\hline $\begin{array}{l}\text { Product } \\
\text { Markets }\end{array}$ & $\begin{array}{l}\text { Reliable enforcement } \\
\text { of liability laws, } \\
\text { efficient dissemination } \\
\text { of information, many } \\
\text { activist consumers }\end{array}$ & $\begin{array}{l}\text { Reliable enforcement } \\
\text { of liability laws, } \\
\text { efficient dissemination } \\
\text { of information, some } \\
\text { activist consumers }\end{array}$ & $\begin{array}{l}\text { Limited enforcement of } \\
\text { liability laws, little } \\
\text { dissemination of } \\
\text { information, few } \\
\text { activist customers }\end{array}$ \\
\hline $\begin{array}{l}\text { Government } \\
\text { regulations }\end{array}$ & $\begin{array}{l}\text { Low, relatively free of } \\
\text { comuption }\end{array}$ & $\begin{array}{l}\text { Moderate, relatively } \\
\text { free of corruption }\end{array}$ & $\begin{array}{l}\text { High, corruption } \\
\text { common }\end{array}$ \\
\hline $\begin{array}{l}\text { Contract } \\
\text { enforcement }\end{array}$ & Predictable & Predictable & Unpredictable \\
\hline Result & $\begin{array}{l}\text { Diversified groups } \\
\text { have many } \\
\text { disadvantages }\end{array}$ & $\begin{array}{l}\text { Diversified groups } \\
\text { have some advantages }\end{array}$ & $\begin{array}{l}\text { Diversified groups } \\
\text { have many advantages }\end{array}$ \\
\hline
\end{tabular}

Table 1: Institutional context drives strategy (Adapted from Khanna and Paleo [3])

\subsection{Business Design}

In the design phase, a methodology is used as a guideline for portfolio design and shown in figure 4 [Leonard: 4]. It is proposed that this methodology should be used only as a guideline, as this can not replace the creativity required in the architectural design of an organisation's portfolio. The strategic issues or design criteria are channelled through this methodology in order to define the most suitable future portfolio. 


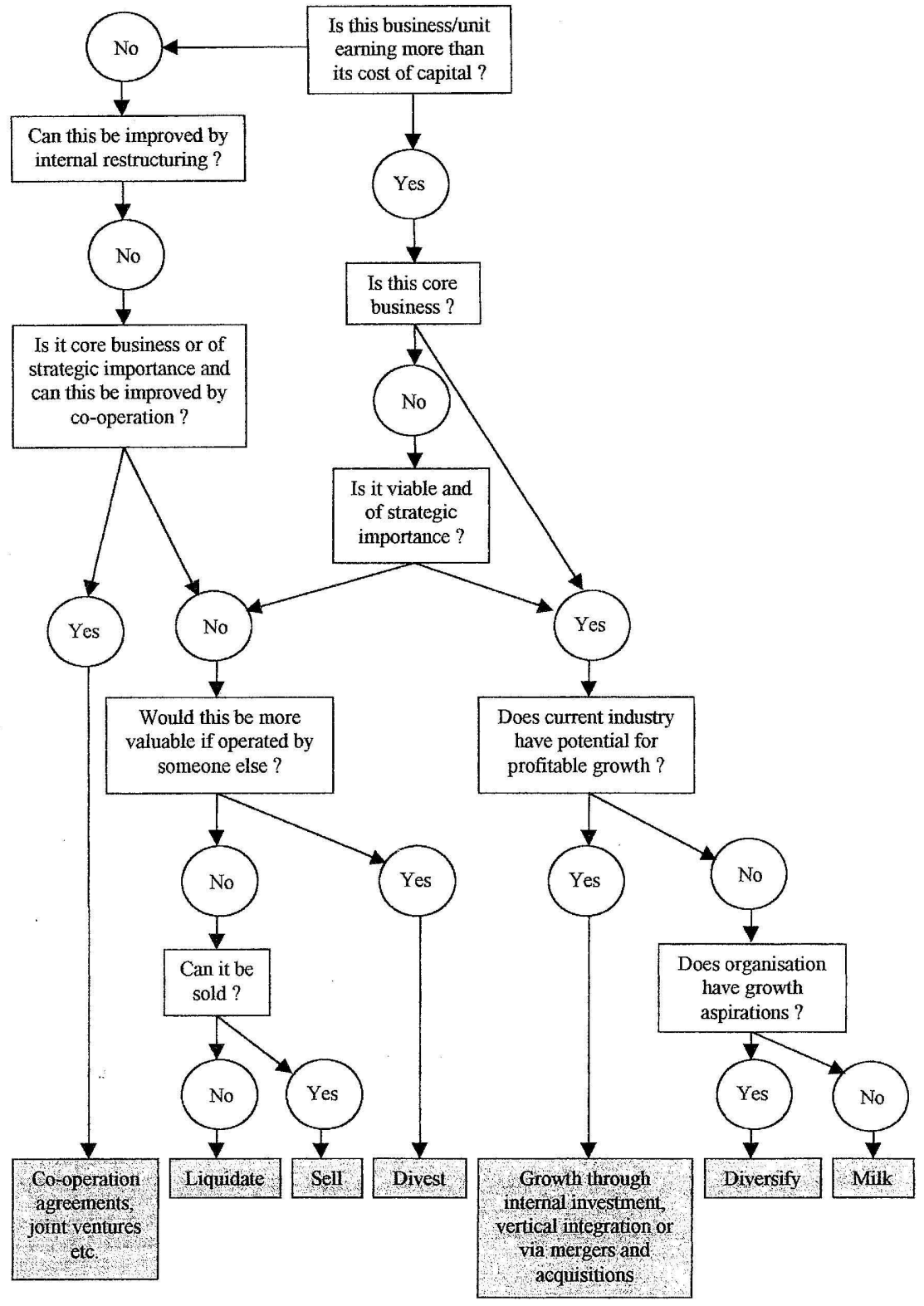

Figure 4: Design Methodology 


\section{- Co-operation agreements, alliances and joint ventures}

An organisation could establish a co-operation agreement with a relevant establishment in order to obtain the specific resources / capabilities or elements required to become profitable, without loosing the specific unit. This should be done if Strategic Business Units or parts of their value chains / streams :

- Are of strategic importance or part of the organisation's core business;

- are not earning more than their cost of capital; and

- can not be improved internally.

\section{- Refocusing}

The second area intends to reduce the scope of the organisation, through refocusing (liquidation, divesting, selling, downscaling, etc.) the business units that :

- Are not earning more than its cost of capital;

- may or may not be of strategic importance or core business; and

- can not be improved in any way (internally or through co-operation).

\section{- Internal investment and vertical integration}

Internal investments and vertical integration (via mergers, acquisitions and joint ventures) should be evaluated as a growth option when the Strategic Business Units :

- Are earning more than their cost of capital;

- fit in with the organisation's core business or are of strategic importance; and

- experience growth opportunities within their industries.

\section{- "Cash cow"}

A typical cash cow approach, as described by the Boston Consulting Group [Thompson: 6], should be adopted by Strategic Business Units when :

- They are earning more than their cost of capital;

- they are the core business or of strategic importance; and

- further growth is not possible or desirable.

\section{- Diversification}

Diversification becomes a strategic necessity when Strategic Business Units :

- Are earning more than their cost of capital;

- are the core business or of strategic importance; and

- further growth in the current industry is not possible; but 
- further growth is desirable.

By applying these guidelines a new portfolio scope may be defined, as well as strategic initiatives that will describe the path leading from the current reality to the future portfolio.

\subsection{Business Transformation}

"Weak leadership can wreck the soundest strategy; forceful execution of even a poor plan can often bring victory."

\section{Sun Tzu}

Moll [5] defines business transformation as being concerned with the implementation of the proposed architecture (in this case the proposed future portfolio). Putting the strategy into effect and getting the organisation moving in the chosen direction calls for a different set of managerial tasks and skills. Whereas crafting strategy is largely an entrepreneurial activity, implementing strategy is largely an internal administrative activity. Successful implementation depends on working through others, organising, motivating, culture building and creating a strong fit between strategy and how the organisation does things. Inherent behaviour does not change just because a new strategy has been announced. Kotter [12] suggests that a well-structured transformation process that is supported by open and honest communication and concern for the employees, must be followed. People who are comfortable with the status quo do not want to believe the need for change. Successful implementation of the desired strategy requires addressing the following main aspects [Leonard: 4] :

- Defining an implementation plan; and

- measuring performance against this plan.

The motivational and inspirational challenge is to build such determined commitment, up and down the ranks, that an enthusiastic organisation-wide campaign emerges to carry out the strategy and meet performance targets. Along with enthusiasm and strategic commitment, must come a unified managerial effort to create a series of strategic supportive "fits". These supportive "fits" are summarised as follows [Thompson: 6] :

- The internal organisational structure must be matched to the strategy.

- The necessary organisational skills and capabilities must be developed.

- Resource and budget allocation must support the strategy.

- The organisation's reward structures, policies, information systems and operating practices all need to reinforce the push for effective strategy execution, as opposed to having a passive role or even acting as obstacles.

- Managers must do things in a manner and style that creates and nurtures a strategic supportive work environment and corporate culture.

The stronger the strategic supportive "fits" created internally, the greater the chances of a successful implementation. 


\section{Conclusion}

By applying the proposed Design Methodology to an organisation's portfolio, in order to align with the changing environment, senior management and corporate strategist may be assisted in understanding and acting on the factors that influence their industries. By augmenting the results from this methodology with creative thinking, a new portfolio may be defined that is in line with the changing environment.

\section{References}

1. GOLDRATT E M and COX J, 1992, The Goal: A process of ongoing improvement, North River Press.

2. GRANT R M, 1998, Contemporary Strategy Analysis, Blackwell Publishers.

3. KHANNA T and PALEO K, 1997, Why Focused Strategies may be wrong for emerging markets, Harvard Business Review, July - August 1997.

4. LEONARD P, 1999, An Engineering approach to organisational diversification and refocusing, Masters dissertation, University of Pretoria.

5. MOLL C M, 1998, An Engineering approach to Business Transformation, $\mathrm{PhD}$ thesis, University of Pretoria.

6. THOMPSON A A and STRICKLAND A J, 1987, Strategic Management: Concepts and Cases, Business Publications Inc.

7. CHAMPY J, 1994, Managing the Reengineering Organisation, Insight, Volume 6 No 1, CSC Cambridge, Spring 1994.

8. DAVENPORT T H 1993, Process Innovation: Reengineering Work through Information Technology, Harvard Business School Press.

9. DAVENPORT T H and SHORT J E, 1990, The New Industrial Engineering: Information Technology and Business Process Redesign, Sloan Management Review, Summer 1990.

10. HAMMER M and CHAMPY J, 1993, Reengineering the Corporation: A Manifesto for Business Revolution, Nicholas Brealey Publishing Ltd.

11. HAMMER M and STANTON S A, 1995, The Reengineering Revolution, Harper Collins Publishers Inc.

12. KOTTER J P 1995, Leading change: Why transformation efforts fail, Harvard Business Review, March-April 1995. 